Article

\title{
Temperature and conductivity as indicators of the morphology and activity of a submarine volcano: Avyssos (Nisyros) in the South Aegean Sea, Greece
}

\author{
Evangelos Bakalis ${ }^{1,2, *}$, Theo J. Mertzimekis ${ }^{1}$, Paraskevi Nomikou ${ }^{3}$, and Francesco Zerbetto ${ }^{2}$ \\ Department of Physics, National Kapodistrian University of Athens, GR-15784 Athens, Greece \\ Dipartimento di Chimica "G. Ciamician", Universita di Bologna, Italy \\ Department of Geology \& Geoenvironment, National Kapodistrian University of Athens, GR-15784 Athens, \\ Greece \\ * email: evangelos.bakalis2@unibo.it
}

\begin{abstract}
The morphology and the activity of a submarine caldera, Avyssos, at the northern part of Nisyros volcano in the South Aegean Sea (Greece), has been studied by means of remotely operated underwater vehicle dives. The recorded time series of temperature and conductivity over the submarine volcano have been analyzed in terms of the Generalized Moments Method. The findings of the mathematical analysis shed light on the volcanic activity, but also on the morphology (shape) of the submarine volcano. The conductivity time series indicates the volcano is at rest in agreement with other types of observations. On the other hand, temperature fluctuations, which in general describe a multifractal process, show that the submarine caldera operates as an open system that interacts with its surroundings. This type of analysis can be used as an indicator for the state of activity and the morphological structure (closed or open system) of a submarine volcano.
\end{abstract}

Keywords: Generalized Moments Method, time series, submarine volcano, Nisyros

\section{Introduction}

Nisyros island is an active volcano at the eastern edge of the Aegean within the Hellenic Volcanic arc and trench system along the convergence zone of the Eurasian and African plates [1,2]. Seismic activity during 1995-1998 affected the island with damage along the western edge of the Mandraki town (located in NW Nisyros), related to the Mandraki fault, which extends northwards under the sea [3]. Several types of studies have been conducted on Nisyros since then, focusing on seismicity [4], tectonics [5], petrology [6], geochemistry [7] and more. Remotely Operated underwater Vehicle (ROV)-based studies have been focused on the geomorphology of the underwater features around Nisyros and explored the volcanic field offshore of the island, mainly along the Nisyros-Yali-Strongyli area [8]. Such information is available for the neighboring Avyssos underwater caldera (see Fig. 1) at the Northeastern part of the volcanic islet of Strongyli, north of Nisyros volcano. The study of underwater volcanic activity of the area can provide important information on the properties of the volcanic system, especially in comparison to the shallow active submarine volcano Kolumbo, NE of Santorini [9-12]. Kolumbo was studied extensively in the summer and fall of 2010 and summer of 2011 using the ROVs "Hercules" and "Argus" of E/V "Nautilus". Among others, a dedicated cruise in the 2010 campaign focused on exploring the unknown volcano-tectonic characteristics of the Nisyros-Yali-Kos region and the associated volcanic field around Nisyros. Both Nisyros and Santorini belong to the same volcanic arc, both have exhibited unrest in the recent past $[4,13]$ and both present potential sources of geohazards $[4,8]$. However, these underwater volcanoes have quite different geomorphology: Kolumbo in Santorini is a bowl-shaped volcano with an elevation difference between its rim and bottom of about $400 \mathrm{~m}$ (maximum depth is $504 \mathrm{~m}$ ) [10], while the Avyssos caldera dimensions are $3 \mathrm{~km}$ in the NW-SE direction and $4 \mathrm{~km}$ in the NE-SW direction with a maximum depth of $673 \mathrm{~m}$ [8]. In addition, there is a hill of about $1 \mathrm{~km}$ length at the center of Avyssos with a 
35 positive relief of about $60-70 \mathrm{~m}$ above the flat sea botto
behavior in the recorded physical and chemical data.
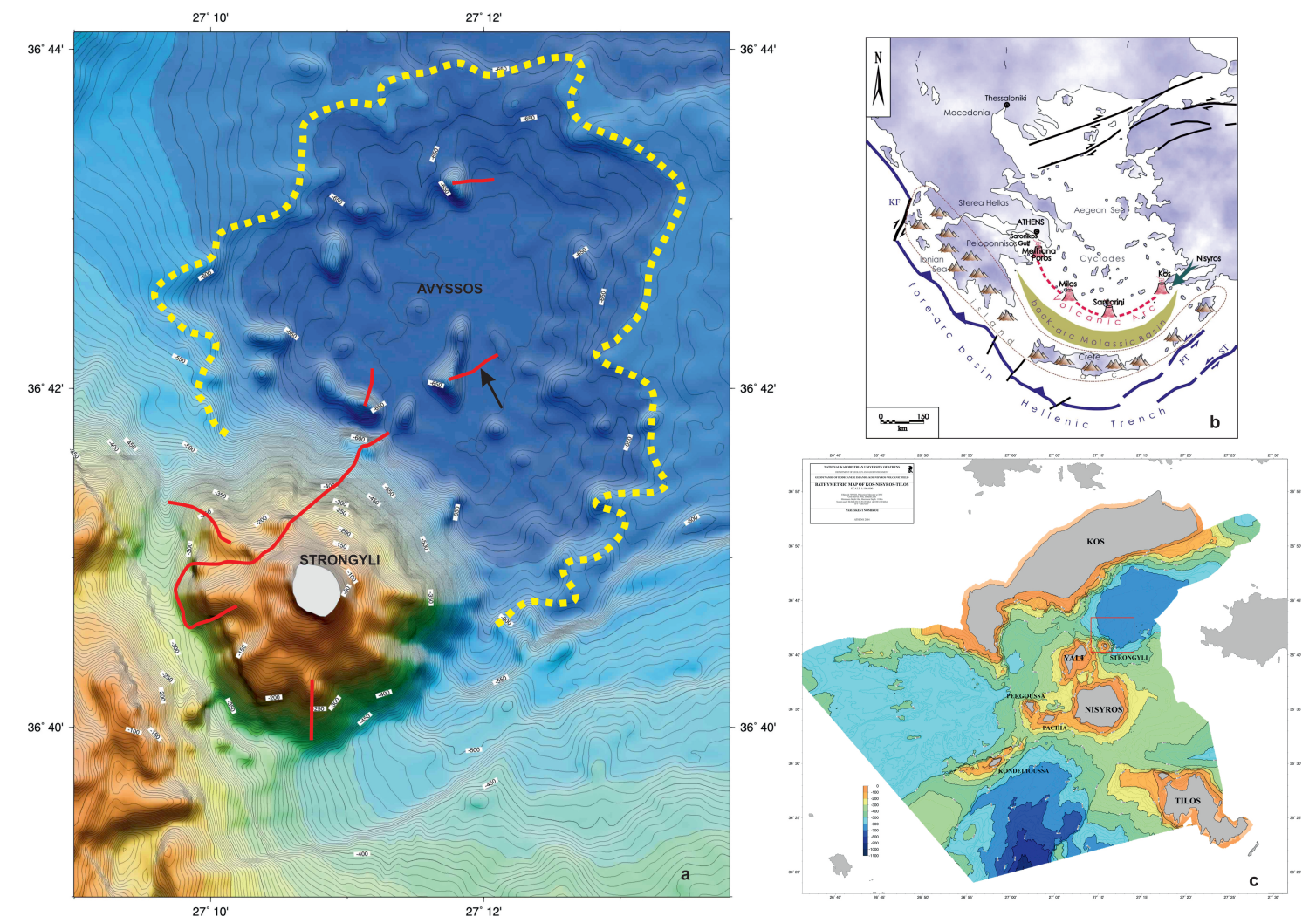

Figure 1. (Left) A bathymetric map of Avyssos off the coast of Nisyros (adopted from [8]). The yellow dashed line roughly defines the borders of Avyssos caldera and the red lines the ROV transects. A black arrow indicates the location of the ROV during data sampling. (Right, top) The geodynamic structure of the Hellenic Arc. (Right, bottom) The extended Kos-Nisyros-Tilos volcanic field in the eastern Aegean Sea is shown in the bottom right inset.

An efficient method to study those characteristics is to employ ROV-based sensors, able to record CTD data (Conductivity, Temperature, Depth) in the water column. In the case of Kolumbo, the character of the depth profiles of temperature, conductivity and salinity over the vent field was directly associated to the morphology of its crater [12]. In addition, Kolumbo's hydrothermal vent activity was recorded as time series of temperature and conductivity during two different periods; in 2010 the volcano exhibited intense activity, while in 2011 its activity decreased significantly. Besides the profound changes in the CTD data, a novel mathematical technique was applied for the first time on the time series to identify the underlying stochastic processes [14] that drive the activity of the volcano.

Due to the different characteristics and volcanic activity in comparison with Kolumbo, Avyssos presents an ideal test cast to examine the applicability of the mathematical method. The absence of hydrothermal vent field activity and the open caldera can serve as the exact opposite benchmarks for the mathematical technique as applied in Kolumbo, which can help identify underlying similarities and differences between the two submarine volcanic structures. As such, based solely on statistical markers, the combined results from the two different submarine volcanoes can potentially serve as geohazard assessors for similar environments where no information is available.

\section{Methodology}

The CTD data were acquired by a pre-calibrated SeaBird FastCAT 49Plus CTD probe mounted on ROV "Hercules", which was tethered to ROV "Argus" receiving power from the ship and transferring 


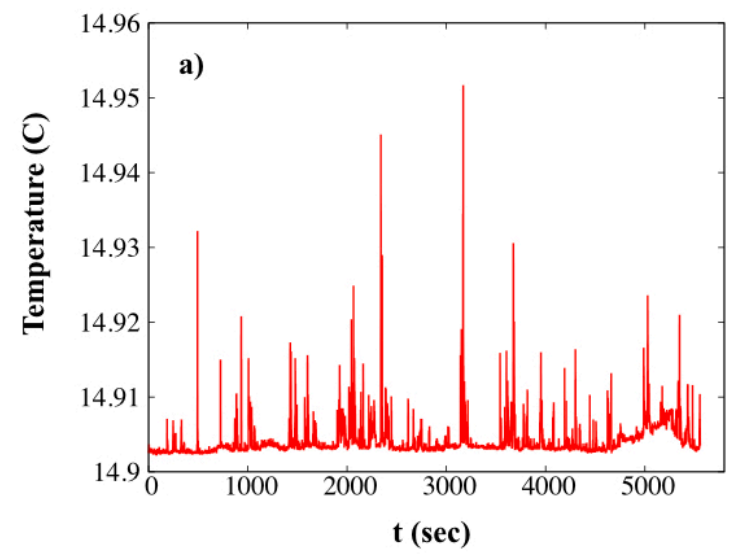

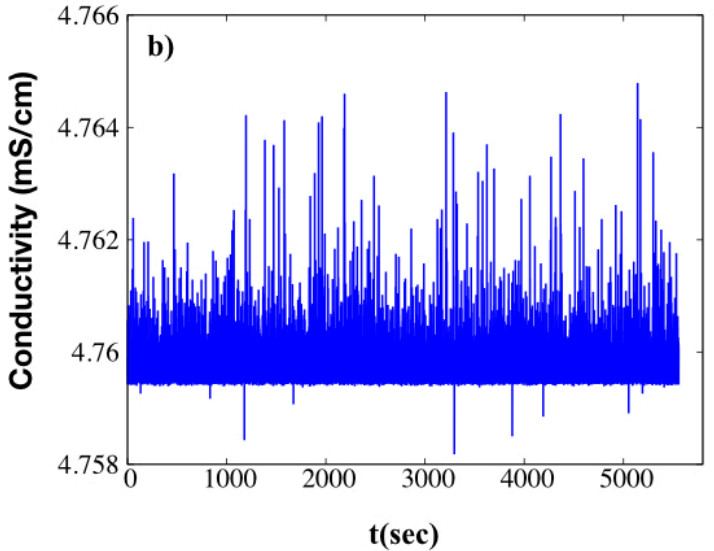

Figure 2. The time series (summer 2010) of (a) temperature, and (b) conductivity. Notice that conductivity changes are very small and present a regularity, instead, temperature variations are a bit larger and possess some irregular peaks.

A first estimate of the behavior of a stochastic process, $x(t)$, can be made in terms of its variance $W(t)=\left\langle x^{2}(t)\right\rangle-\langle x(t)\rangle^{2}$. In general, the variance in time of a stochastic process scales as:

$$
W(t)=\frac{K_{\gamma} t^{\gamma}}{\Gamma(1+\gamma)}
$$

where $K_{\gamma}$ is a generalized coefficient expressed in proper units, e.g. if eq. 1 describes the variance of temperature then the units are $\mathrm{deg}^{2} \cdot \mathrm{s}^{-\gamma}$. Eq. 1 can serve as a tool for a first classification of the stochastic process based on the value of the exponent $\gamma$. A stochastic process is classified as sub-normal or anti-persistent for $0<\gamma<1$, Brownian under certain conditions for $\gamma=1$ (see discussion below), super normal or persistent for $1<\gamma<2$, ballistic for $\gamma=2$, and stationary for $\gamma=0$.

For discrete data time series eq. 1 takes the form:

$$
W(\Delta, T)=\frac{1}{M} \sum_{i=1}^{M} \frac{1}{T-\Delta} \sum_{n=1}^{T-\Delta}\left(x_{i}(n+\Delta)-x_{i}(n)\right)^{2}-\left(\frac{1}{M} \sum_{i=1}^{M} \frac{1}{T-\Delta} \sum_{n=1}^{T-\Delta}\left(x_{i}(n+\Delta)-x_{i}(n)\right)\right)^{2}
$$

where $M$ is the number of experiments repeated under exactly the same conditions, so that eq. 2 expresses the ensemble averaged over all records, while for $M=1$ the first summation is omitted. $T$ is the length of the recorded trajectory, and $\Delta$ is the lag time, which is the elapsed time between two measurements and plays the role of time for discrete data sets.

More insights on the mechanisms governing a stochastic process can be extracted by using sophisticated methods appropriate for time series analysis. Among them [16-21] the Generalized Moments Method (GMM) is generally the more robust and works well even for short time series [22]. It has been successfully applied in numerous fields [14,23-26]. Considering a time series in the form 
$x(n)$ with $n=1,2, \ldots, N$, where $N$ is the total number of steps (measurements), and if the minimum lag time defined as the reciprocal of the sampling rate, $f$, or in other words the time elapsed between two consecutive measurements is $\tau$, then the total length of the trajectory is $T=N \times \tau$. The method works as follows:

- Step 1: Construction of time series with different lag times; we create new time series, $y_{n}(\Delta)$, which contain the absolute change of the values between two points of the initial series that are apart by $\Delta$. $y_{n}(\Delta)=\left(x(n+\Delta)^{2}-x(n)^{2}\right)^{1 / 2}$ for $n=1,2, \ldots, T-\Delta$, and for $\Delta=\tau, 2 \tau, 3 \tau, \ldots, \tau_{\max } \tau$. In order to have statistical reliable results, we define the maximum lag time as one tenth of the maximum length of the original time series, $\tau_{\max }=\frac{N}{10}$, creating thus $N / 10$ new time series of length $N-\Delta$ each.

- Step 2: Estimate of the statistical moments;

We estimate the moments of $y_{n}(\Delta)$ according to eq. 3 :

$$
\rho(q, \Delta)=\frac{1}{T-\Delta} \sum_{n=1}^{T-\Delta}\left(y_{n}(\Delta)\right)^{q}
$$

where even fractional values of the moment, $q$, are taken into account. We use only positive values of the moments [27]. The values of the moments in the range $0<q \leq 2$ are responsible for the core of the probability density function (pdf), while moments higher than $2, q>2$, contribute to the tails of the pdf.

- Step 3: In general, the moments will scale according to eq. 4:

$$
\rho(q, \Delta) \approx \Delta^{z(q)}
$$

where $z(q)$ is the structure function whose shape gives information on the stochastic mechanism(s) governing the motion.

Stochastic processes can be of a varying degree of complexity. When the structure function takes the simple form $z(q)=H q$, there is a direct relation of exponent $\gamma$ of eq. 1 and the cofactor of the structure function, namely $H=2 \gamma$, where $H$ is the Hurst exponent. If $z(q)$ is a linear function of $q$ or is linear in different portions (bilinearity), then the mechanisms that likely govern the stochastic sequence are additively decomposable, e.g. fractional Brownian motion (fBm), fractional Gaussian noise (fGn), Lévy flights and/or walks. Linear dependency of $z(q)$ on $q$ describes monofractal processes. Instead, if $z(q)$ has a convex shape as a function of the order of the moment, $q$, then multiplicative processes drive the stochastic sequence, which also means that $H$ is function of $q$. For some values of $q$ the exponents $H(q)=z(q) / q$ are associated with special features. For $q=1$, the value of $H(1)$ describes the scaling behavior of the absolute value of the increments, and is identified with the Hurst exponent if the process is monofractal. For $q=2$, the value of $H(2)$ is associated to scaling exponent of the autocorrelation function and is related to the power spectrum [28]. Of all types of multifractals, universal multifractals are likely to be ubiquitous [29-31], and the structure function reads [31].

$$
z(q)=H q-\frac{C}{a-1}\left(q^{a}-q\right)
$$

For $a=1$, eq. 5 takes the form $z(q)=H q-C q \log (q)$ and the distribution draws changes from a Cauchy-Lorentz distribution. For $a=2$, eq. 5 reads $z(q)=H q-C\left(q^{2}-q\right)$ and the distribution draws changes from a lognormal distribution.

\section{Results}

We estimate the variance for both the temperature and conductivity time series depicted in Fig. 2, the results are illustrated in Fig. 3. The variance for the conductivity time series (right panel in Fig. 3) 
is constant as a function of the lag time, $\Delta$. This behavior indicates that conductivity measurements describe a stationary process, which in the present case by also combining results from moments analysis (see below) points to a submarine volcano with no fingerprints of any hydrothermal vent field activity. In contrast, the temperature time series shows a power-law behavior for small lag times followed by an almost stationary regime for longer lag times. The variance of temperature is formed
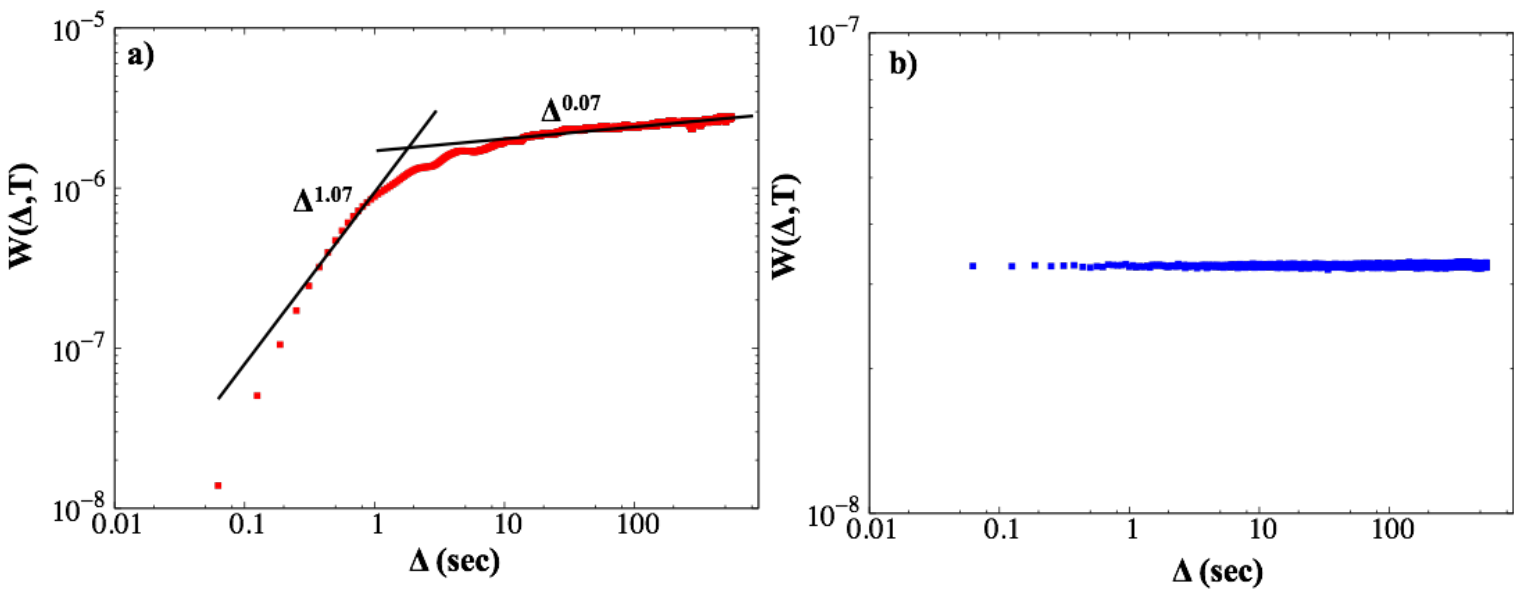

Figure 3. The logarithmic plots of variance estimated by using eq. 2 versus the lag time for a) temperature, and b) conductivity

by two discrete regimes (left panel in Fig. 3), with a turning point at $\Delta=1$. We fit the variance of temperature with a function of the form, $W(\Delta)=b \Delta^{\gamma}$. For the first regime, $1 / 16<\Delta<1$, we find that $\gamma=1.073 \pm 0.051$, and for the second regime the value of the exponent is $\gamma=0.0750 \pm 0.0003$. In the first regime the obtained value of 1.073 indicates a process which potentially can be characterized as Brownian since $\gamma \approx 1$. However, the form of the structure function (Fig. 5) does not support this hypothesis (see also discussion in [26]) and reveals information useful for characterizing the system, as closed or open, i.e. a bowl-shaped caldera vs. a caldera with no large difference between its rim and its bottom, respectively. In the second regime, the estimated exponent shows clearly a stationary process, suggesting that all measurements which are at least $1 \mathrm{~s}$ apart share the same properties. We estimated
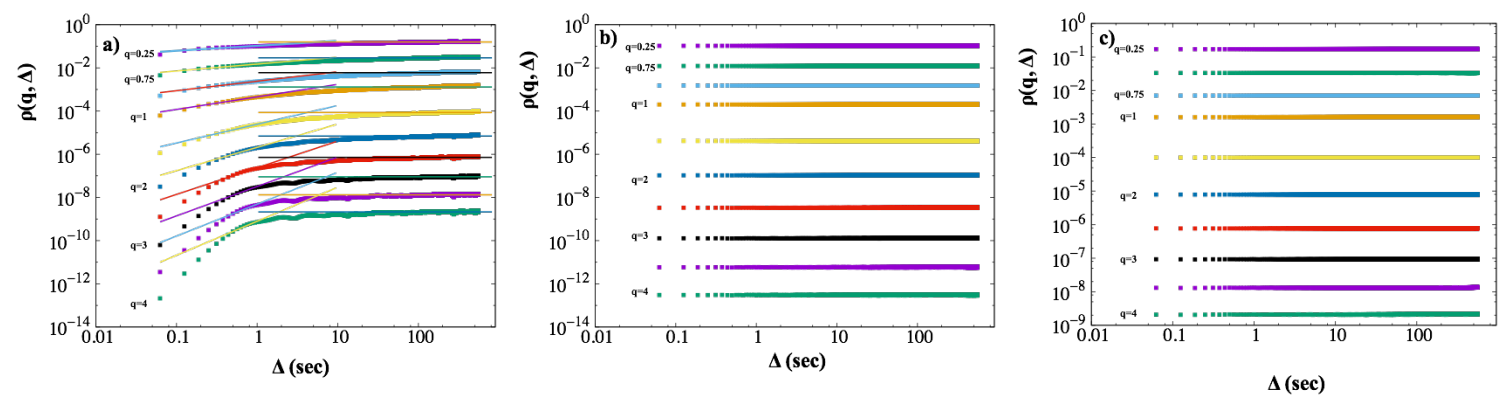

Figure 4. Generalized moments of (a) temperature, and (b) conductivity as functions of the lag time, $\Delta$, for different moments $q$, (c) The same as (a) for temperature shuffled time series.

the moments for both temperature and conductivity by using eq. 3 . The results are illustrated in Fig. 4. For conductivity, all moments are constant confirming the stationarity of the recorded data and indicating that the volcano is at rest (Fig. 4b). By comparing this to Kolumbo's rest period, where the conductivity time series are multifractal, a result of the outgoing ions and gases from the hydrothermal field, one can conclude that a hydrothermal field is rather absent in this case. For temperature, all the 


$$
\text { (1) }
$$

moments show the existence of two distinct regimes with a turning point at $\Delta=1 \mathrm{~s}$. For lag times greater than $1 \mathrm{~s}$ all moments are parallel to the time axis meaning that the temperature recorded at a fixed location over the volcanic field has been equilibrated with the temperature of the surrounding water. For lag times smaller than $1 \mathrm{~s}$ the moments of temperature have been fitted by eq. 4 . The obtained exponents are used to find the form of the structure function (see Fig. 5). Every point (red squares) depicted in Fig. 5 is the value of the structure function for each moment. The structure function, $z(q)$, poses a convex shape as a function of the order of the moment, $q$, suggesting the existence of a multifractal process. In other words, multifractality underlines the existence of two or more stochastic processes acting in a multiplicative way and defining the overall behavior of the temperature time series for small lag times. The data presented in Fig. 5 are best fitted by eq. 4 for $a=2$, lognormal

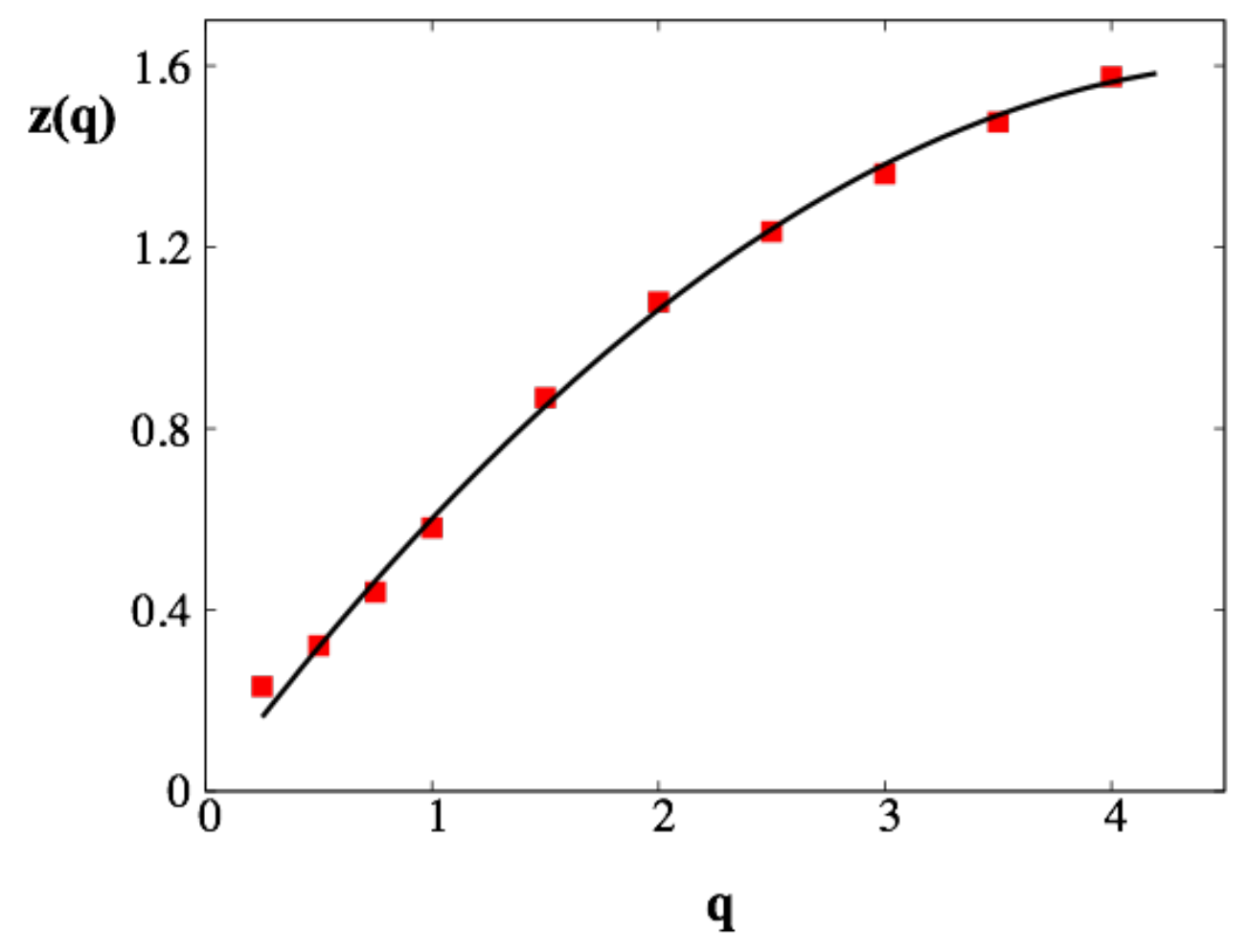

Figure 5. The structure function $\mathrm{z}(\mathrm{q})$ versus the order of the moment $\mathrm{q}$ for temperature time series.

distribution. The parameters $H$ and $C$ have values of $H=0.601 \pm 0.011$, and $C=0.070 \pm 0.005$. A lognormal distribution implies the existence of a multiplicative effect, which is the result of at least two random processes. In our case, such an effect may be caused by a random process causing temperature variations inside the crater and a random process related to the variations of the temperature of the surroundings. The overall effect says that the volcano area operates as an open system where a rapid mixing (first regime) between the outflushing hydrothermal fluid from the vents (if any) with its surroundings washes out any small temperature variations and drives the volcanic field to equilibrium (stationary second regime). In the first regime, the observed multifractality is likely due to a) a broad distribution of the probability values and b) long-range correlations. Randomization of the original time series to produce a shuffled time series can give insights on the origin of multifractality. If GMM analysis retains multifractal behavior for the shuffled time series, then the broad distribution of probability values is the origin of multiple and non-decomposable time scales. In this case, the system tries to maximize information. Instead, if for shuffled time series the GMM analysis shows random or stationary behavior, existing long-range correlations are responsible for multifractality. Performing 
the GMM analysis for the shuffled temperature time series we found that all moments are constant and independent of the lag time, see Fig. 4c. Long-range correlations are responsible for the observed dynamics of temperature in the first regime. These correlations are likely caused by the fast mixing of the two different fluid-banks.

Analyzing the recorded time series of temperature and conductivity just above the Avyssos submarine volcano we found that a) the volcano is at rest and there is no activity in terms of emerging gases and ionic particles, and $b$ ) the temperature presents an initial multiplicative behavior reflecting the mixing of at least two different random processes, which then turns to stationarity.

The early-time temperature behavior is an indicator that Avyssos submarine volcano acts as an open system, and this observation is in line with geomorphological mapping of the volcano [8] and visual observations with the ROV that showed no activity [15]. In the case of the Kolumbo vent field, where the same methodology has recently been applied to analyze temperature and conductivity recorded over the active vents [14] it was observed that when Kolumbo was at rest, the conductivity for early times presented a multifractal behavior mirrored on the outcoming gases and ions from the vent field, while the temperature was a stationary process for all times, thus indicating that the system operated as a closed one. The significance in the context of the present work is the fact that the combined results provide the two extremes of the ranges showing the GMM can be applied to characterize any other system, open or closed. Based on these findings, we propose the above methodology of analysis as an indicator for the state of activity and the shape (closed or open systems) of a submarine volcano featuring a volcanic field. On one hand, when conductivity presents a multifractal character it also serves as an indication of vent activity, while if conductivity behaves as a stationary process then activity is not present. On the other hand, if temperature displays a stationary behavior, independent of the lag time, the system operates as a closed one in relation to its surroundings, while if multifractality is observed for small lag times the system is an open one.

\section{Conclusions}

The temperature and conductivity time series recorded by a ROV just above the seafloor at the underwater caldera of Avyssos have been analyzed with the GMM method. The analysis showed that when the volcano is at rest, conductivity is a stationary process, and the crater of the volcano is in direct contact with the overlying water environment, thus defining an open system, as shown by the temperature early lag times behavior. Comparing the results of the same method with the case of Kolumbo submarine volcano, where conductivity showed the existence of multiple time scales and temperature was stationary, we suggest that the behavior of these two properties can serve as an indicator for the state of activity (conductivity) and the physical setting, open or closed, of the submarine volcano (temperature). The present methodology can be useful especially when insights are needed for poorly known deep-sea volcanoes, where in situ measurements by means of the use of submarine robotic technologies are either too expensive or even technically impossible. Further application of the technique on other volcanic systems is required to confirm its applicability as a universal geohazard warning method.

Acknowledgments: We thank the crew of the E/V "Nautilus" for their assistance during expeditions in 2010 and 2011.

Author Contributions: EB and TJM contributed to data preparation and mathematical analysis. PN led the process of data sampling and map reconstruction. All authors contributed in the manuscript preparation, data assessment and interpretation.

Conflicts of Interest: The authors declare no conflict of interest.

\section{References}

1. Papanikolaou, D.; Nomikou, P. Tectonic structure and volcanic centres at the eastern edge of the Aegean volcanic arc around Nisyros Island. Bull. Geol. Soc. Greece 2001, 34, 289-296. 
2. Nomikou, P.; Papanikolaou, D.; Dietrich, V. Geodynamics and Volcanism in the Kos-Yali-Nisyros Volcanic Field. Nisyros Volcano; Dietrich, V.; Lagios, E., Eds. Springer, 2018, pp. 13-56.

3. Nomikou, P.; Papanikolaou, D. Extension of active fault zones on Nisyros volcano across the Yali-Nisyros Channel based on onshore and offshore data. Marine Geophysical Research 2011, 32, 181-192.

4. Papadopoulos, G.A.; Sachpazi, M.; Panopoulou, G.; Stavrakakis, G. The volcanoseismic crisis of 1996-97 in Nisyros, SE Aegean Sea, Greece. Terra Nova 1998, 10, 151-154.

5. Longchamp, C.; Bonadonna, C.; Bachmann, O.; Skopelitis, A. Characterization of tephra deposits with limited exposure: the example of the two largest explosive eruptions at Nisyros volcano (Greece). Bulletin of Volcanology 2011, 73, 1337-1352.

6. Bachmann, O.; Deering, C.D.; Ruprecht, J.S.; Huber, C.; Skopelitis, A.; Schnyder, C. Evolution of silicic magmas in the Kos-Nisyros volcanic center, Greece: a petrological cycle associated with caldera collapse. Contributions to Mineralogy and Petrology 2012, 163, 151-166.

7. Brombach, T.; Caliro, S.; Chiodini, G.; Fiebig, J.; Hunziker, J.C.; Raco, B. Geochemical evidence for mixing of magmatic fluids with seawater, Nisyros hydrothermal system, Greece. Bulletin of Volcanology 2003, 65, 505-516.

8. Nomikou, P.; Bell, K.; Vougioukalakis, G.; Livanos, I.; Martin Fero, J. Exploring the Nisyros Volcanic Field, p.27, in New Frontiers in Ocean Exploration: The E/V Nautilus 2010 Field Season. K.L.C. Bell and S.A. Fuller, eds. Oceanography 2011, 24(1) Supplement.

9. Sigurdsson, H.; Carey, S.; Alexandri, M.; Vougioukalakis, G.; Croff, K.; Roman, C.; Sakellariou, D.; Anagnostou, C.; Rousakis, G.; Ioakim, C.; Goguo, A.; Ballas, D.; Misaridis, T.; Nomikou, P. Marine investigations of Greece's Santorini Volcanic Field. EOS 2006, 87, 337-342.

10. Nomikou, P.; Carey, S.; Papanikolaou, D.; Bell, K.C.; Sakellariou, D.; Alexandri, M.; Bejelou, K. Submarine volcanoes of the Kolumbo volcanic zone $\{\mathrm{NE}\}$ of Santorini Caldera, Greece. Glob. Planet. Change 2012, 90-91, 135-151.

11. Kilias, S.P.; Nomikou, P.; Papanikolaou, D.; Polymenakou, P.N.; Godelitsas, A.; Argyraki, A.; Carey, S.; Gamaletsos, P.; Mertzimekis, T.J.; Stathopoulou, E.; Goettlicher, J.; Steininger, R.; Betzelou, K.; Livanos, I.; Christakis, C.; Bell, K.C.; Scoullos, M. New insights into hydrothermal vent processes in the unique shallow-submarine arc-volcano, Kolumbo (Santorini), Greece. Sci. Rep. 2013, 3, 2421.

12. Christopoulou, M.E.; Mertzimekis, T.J.; Nomikou, P.; Papanikolaou, D.; Carey, S.; Mandalakis, M. Influence of hydrothermal venting on water column properties in the crater of the Kolumbo submarine volcano, Santorini volcanic field (Greece). Geo-Mar. Lett. 2016, 36, 15-24.

13. Parks, M.; Biggs, J.; England, P.; Mather, T.; Nomikou, P.; Palamartchouk, K.; Papanikolaou, X.; Paradissis, D.; Parsons, B.; Pyle, D.; Raptakis, C.; Zacharis, V. Evolution of Santorini Volcano dominated by episodic and rapid fluxes of melt from depth. Nature Geoscience 2012, 5.

14. Bakalis, E.; Mertzimekis, T.J.; Nomikou, P.; Zerbetto, F. Breathing modes of Kolumbo submarine volcano (Santorini,Greece). Scientific Reports 2017, 7, 46515.

15. E/V “Nautilus" Cruise logs NA007 and NA011. unpublished, 2010.

16. Kolmogorov, A.N. A refinement of previous hypotheses concerning the local structure of turbulence in a viscous incompressible fluid at high Reynolds number. J. Fluid Mech. 1962, 13, 82-85.

17. Hansen, L.P. Large Sample Properties of Generalized Method of Moments Estimators. Econometrica 1982, 50, 1029-1054.

18. Andersen, K.; Castiglione, P.; Mazzino, A.; Vulpiani, A. Simple stochastic models showing strong anomalous diffusion. Eur. Phys. J. B 2000, 18, 447-452.

19. Peng, C.K.; Buldyrev, S.V.; Havlin, S.; Simons, M.; Stanley, H.E.; Goldberger, A.L. Mosaic organization of DNA nucleotides. Phys. Rev. E 1994, 49, 1685-1689.

20. Kantelhardt, J.W.; Zschiegner, S.A.; Koscielny-Bunde, E.; Havlin, S.; Bunde, A.; Stanley, H. Multifractal detrended fluctuation analysis of nonstationary time series. Physica A 2002, 316, 87-114.

21. Scafetta, N.; Grigolini, P. Scaling detection in time series: Diffusion entropy analysis. Phys. Rev. E 2002, $66,036130$.

22. Barunik, J.; Kristoufek, L. On Hurst exponent estimation under heavy-tailed distributions. Physica A 2010, $389,3844-3855$.

23. Bakalis, E.; Hofinger, S.; Venturini, A.; Zerbetto, F. Crossover of two power laws in the anomalous diffusion of a two lipid membrane. J. Chem. Phys. 2015, 142. 
24. Sändig, N.; Bakalis, E.; Zerbetto, F. Stochastic analysis of movements on surfaces: The case of $\{\mathrm{C} 60\}$ on Au(1 1 1). Chem. Phys. Lett. 2015, 633, 163-168.

25. Parent, L.R.; Bakalis, E.; Ramirez-Hernandez, A.; Kammeyer, J.K.; Park, C.; de Pablo, J.; Zerbetto, F.; Patterson, J.P.; Gianneschi, N.C. Directly Observing Micelle Fusion and Growth in Solution by Liquid- Cell Transmission Electron Microscopy. J. Am. Chem. Soc. 2017, 139, 17140-17151.

26. Parent, L.R.; Bakalis, E.; Proetto, M.; Li, Y.; Park, C.; Zerbetto, F.; Gianneschi, N.C. Tackling the Challenges of Dynamic Experiments Using Liquid-Cell Transmission Electron Microscopy. Acc. Chem. Res. 2018, 51, 3-11.

27. Barabasi, A.L.; Vicsek, T. Multifractality of self-affine fractals. Phys. Rev. A 1991, 44, 2730.

28. Flandrin, P. On the Spectrum of Fractional Brownian Motions. IEEE Transactions on Information Theory 1989, 35, 197-199.

29. Schertzer, D.; Lovejoy, S. Physical modeling and analysis of rain and clouds by anisotropic scaling multiplicative processes. J. Geophys. Res. 1987, 92, 9693-9714.

30. Schertzer, D.; Lovejoy, S. Universal Multifractals Do Exist!: Comments on "A Statistical Analysis of Mesoscale Rainfall as a Random Cascade". Journal of Applied Meteorology 1997, 36, 1296-1303.

31. Lovejoy, S.; Schertzer, D. Multifractals and rain. New Uncertainty Concepts in Hydrology and Water Resources 1995, pp. 61-103. 